\title{
EVOLUĈ̣̃O BIOLÓGICA COMO EIXO INTEGRADOR DA BIOLOGIA EM LIVROS DIDÁTICOS DO ENSINO MÉDIO
}

\author{
Jeronymo Dalapicolla* \\ Victor de Almeida Silva** \\ Junia Freguglia Machado Garcia***
}

RESUMO: O Programa Nacional do Livro Didático (PNLD) prevê a universalização e a avaliação dos livros, levando em conta alguns documentos oficiais. Esses documentos aconselham que os conteúdos de biologia sejam pautados em explicações ecológicas e evolutivas, de forma interdisciplinar, com a evolução funcionando como um eixo integrador do conhecimento. Baseando-se na Análise de Conteúdo de Bardin e na Estrutura Conceitual da Biologia de Mayr, foram examinados os conteúdos referentes ao filo dos cordados em três coleções didáticas. O objetivo foi avaliar como esses materiais abordam a evolução. Notou-se que os livros didáticos utilizam os conceitos evolutivos de forma escassa e superficial. A forma mais comum é a descritiva, com o acréscimo de termos evolutivos ou que remetem à evolução.

Palavras-chave: Evolução. Análise de Conteúdo. Livro Didático.

\section{EVOLUCIÓN COMO EJE INTEGRADOR DE LA BIOLOGÍA EN LIBROS DIDATICOS DE LA SECUNDARIA}

RESUMEN: El Programa Nacional do Livro Didático (PNLD) prevé la universalización y la evaluación de los libros, teniendo en cuenta algunos documentos oficiales. Eses documentos aconsejan que los contenidos de biología estén pautados en explicaciones ecológicas y evolutivas de forma interdisciplinaria, con la evolución funcionando como un eje integrador del conocimiento. Basándose en el Análisis de Contenido de Bardin y en la Estructura Conceptual de la Biología de Mayr, fueron examinados los contenidos referentes al filo de los cordados en tres colecciones didácticas. El objetivo fue evaluar como eses materiales abordan la evolución. Notase que los libros didácticos utilizan de los conceptos evolutivos de forma escasa y superficial. La forma más común es la descriptiva, agregando términos evolutivos o que remiten a la evolución.

Palabras clave: Evolución, Análisis de Contenido, Libro Didáctico

\footnotetext{
${ }^{*}$ Mestre em Biologia Animal pela Universidade Federal do Espírito Santo (Ufes). Foi professor do Ensino Fundamental e Médio do Governo do Estado do Espírito Santo. Doutorando em Ecologia Aplicada pela Escola Superior de Agricultura "Luiz de Queiroz" da Universidade de São Paulo (ESALQ/USP).

E-mail: jdalapicolla@gmail.com

* *Biólogo e professor do Ensino Fundamental e Médio. E-mail: v.victors@hotmail.com

** * Doutora em Educação pela Universidade Federal de Minas Gerais (UFMG). Professora do Departamento de Teorias do Ensino e Práticas Educacionais da Universidade Federal do Espírito Santo (Ufes).

E-mail: junia.freguglia@gmail.com
} 
EVOLUTION AS A UNIFYING THEME IN THE HIGH SCHOOL BIOLOGY TEXTBOOKS

ABSTRACT: Programa Nacional do Livro Didático (PNLD) aims to universalize the textbooks and to evaluate these materials based on official documents. In biology for high school official documents advise that contents should be guided by ecological and evolutionary explanations in an interdisciplinary method and that evolution should work as a central theme. Based on Bardin's Content Analysis and Mayr's Conceptual Framework of Biology the contents concerning the phylum Chordata were examined in three textbook collections approved by PNLD. The aim was to evaluate how textbooks approved for student's use discuss evolution. This study showed that textbooks utilize evolution superficially and sparsely. The most common use is in descriptions with addition of evolutionary concepts or terms that refer to evolution.

Keywords: Evolution. Content Analysis. Textbooks. 


\section{INTRODUÇÃO}

A política educacional brasileira investe no uso de livros didáticos por meio de iniciativas como o Programa Nacional do Livro Didático (PNLD) que é responsável pela avaliação e pela distribuição dos livros didáticos nas escolas públicas brasileiras. A qualidade desses livros é considerada fundamental para melhorias na educação do país já que o livro didático ainda é o principal recurso disponível para apoiar a atividade dos professores e dos alunos no cotidiano escolar (CARNEIRO et al., 2005; LEÃO e MEGID-NETO, 2006; VASCONCELOS e SOUTO, 2003).

A partir de 2005, o Programa Nacional do Livro Didático para o Ensino Médio (PNLEM), um segmento do PNLD, passou a avaliar os livros didáticos de biologia do Ensino Médio. O objetivo da avaliação é analisar quais livros didáticos possuem critérios mínimos de qualidade para serem recomendados para compra pelo Ministério da Educação. Essas avaliações geraram guias para auxiliar os professores durante as escolhas dos livros e foram publicados em 2007, 2008 e 2011 (BRASIL, 2008; 2011; EL-HANI et al., 2011; XAVIER et al., 2006).

Historicamente, além das medidas avaliativas do PNLD, a adoção dos Parâmetros Curriculares Nacionais (PCN), das Orientações Curriculares Nacionais (OCN) e das Diretrizes Curriculares Nacionais (DCN) também ajudou a aperfeiçoar os livros didáticos (LEÃO e MEGID-NETO, 2006). Esses documentos tentam ajustar o currículo escolar de todo o país (LEÃO e MEGID-NETO, 2006; BRASIL, 2006) e foram ou são usados como critérios de eliminação dos livros pelo PNLD, juntamente com outros documentos oficiais, como, por exemplo, a Constituição Federal e o Estatuto da Criança e do Adolescente (BRASIL, 2008). Assim, os novos livros que têm sido produzidos e os antigos que foram reformulados são baseados nesses documentos, visando à aprovação na avaliação do PNLD (AMARAL, 2006). Desse modo, é de esperar que haja sintonia e articulação entre diretrizes, programas de avaliação dos liuros didáticos e sistema de avaliação escolar (LEÃO e MEGID-NETO, 2006, p. 35).

No ensino de biologia para o nível médio da educação básica, os documentos oficiais aconselham que os conteúdos ensinados sejam pautados em explicações ecológicas e evolutivas, de forma interdisciplinar (BRASIL, 2006; SANTOS e CALOR, 2007; SILVA-PORTO et al., 2007) e que a evolução deve permear todas as disciplinas que constituem a biologia (ZAMBERLAN e SILVA, 2009) "como elemento central e unificador no estudo da Biologia” (BRASIL, 2006, p. 22).

Harrison (2001 apud RIDLEY, 2006) definiu a evolução como "mudança ao longo do tempo por meio da descendência com modificação” (p. 28), e a sua importância não fica restrita apenas ao campo da biologia evolutiva. Alguns autores como Dobzhansky, Futuyma e Gould destacam a evolução como elemento unificador dos conhecimentos de toda a Biologia (GOEDERT, 2004). "Ela afeta, por extensão, quase todos os outros campos do conhecimento e deve ser considerado um dos conceitos mais influentes do pensamento ocidental" (FUTUYMA, 2006, p. 16). 
Segundo Dobzhansky (1973), o entendimento das Ciências Biológicas só será completo com a compreensão da evolução e, sem ela, essa ciência se transforma em um aglomerado de fatos que não possui representação. Contudo, muitos livros didáticos em uso pelo país ainda apresentam explicações sem fundamentação na ecologia e/ou evolução para certos fenômenos biológicos (AZEVEDO, 2007). Esse tipo de abordagem faz com que os professores procurem outras explicações para os fatos, que não são científicas, comprometendo a aprendizagem dos alunos (BELLINI, 2006; AZEVEDO, 2007). Além disso, os princípios evolutivos têm sido frequentemente mal-interpretados, por exemplo, "evolução" é geralmente equiparada a "progresso” (FUTUYMA, 2006; BELLINI, 2006; ROMA, 2011).

Ernst Mayr defende que a biologia pode ser dividida em dois campos, o da Biologia Funcional e o da Biologia Evolutiva (MAYR, 1998; 2005), afirmando que há duas formas de compreender as causas de um fenômeno, sendo uma através da explicação das causas próximas (funcionais) e outra através das causas últimas (evolutivas). Segundo Mayr (2008):

\footnotetext{
Todas as atividades ou processos [biológicos] que envolvem instruções de um programa são causas próximas [...] [como] a causação de processos fisiológicos, de desenvolvimento e comportamentais que são controlados por programas genéticos e somáticos. [...] Causas últimas ou evolutivas são aquelas que conduzem à origem de novos programas genéticos ou a modificações de programas existentes - em outras palavras, todas as causas que levam às mudanças ocorridas durante o processo de evolução. (p. 101)
}

Assim, um fenômeno biológico suscita questões que podem ser indagadas em relação à sua função e, também, às causas que respondem pela origem e pela evolução do processo (FREGUGLIA, 2009). Mayr ainda afirma que nenhum fenômeno biológico pode ser plenamente resolvido sem a elucidação das suas causas próximas e últimas (MAYR, 1998).

Por essa visão, os porquês da biologia nos livros didáticos poderiam ser explicados pelas causas próximas, não associando a evolução aos diversos assuntos tratados nesse material e também pelas causas últimas, o que estaria coerente com os preceitos dos documentos oficiais relativos ao tratamento da evolução como eixo integrador do conhecimento biológico. Espera-se, assim, que os livros didáticos de biologia aprovados pelo PNLD sigam as recomendações oficiais e tentem abordar os porquês da biologia na perspectiva das causas últimas, com a evolução sendo um eixo para o ensino de biologia.

Além desses argumentos, sob o ponto de vista das questões sobre a linguagem, que atualmente orientam diversas pesquisas no campo da Educação em Ciência, a abordagem narrativa própria da evolução proporciona maior aproximação com os modos de dizer dos estudantes. Essa aproximação pode constituir uma via para o desenvolvimento do pensamento biológico e para a aprendizagem em ciências (BRUNER, 1997). Bruner defende a adoção da narrativa pelas escolas como ferramenta para o ensino das diversas disciplinas, sob o argumento de que os estudantes "produzem e compreendem as histórias, sentindo-se confortados por elas" 
(BRUNER, 1997, p. 18). Ainda segundo o autor, "as proposições lógicas são mais facilmente compreendidas quando embutidas em uma história em andamento" (BRUNER, 1997, p. 18). Isso ocorre porque os discursos dos estudantes, como afirma Bruner, são constituídos de realidades narrativizadas, próprias do cotidiano.

Dessa forma, o objetivo desse trabalho é analisar como livros didáticos de biologia, aprovados pelo PNLD, abordam um conteúdo da zoologia na perspectiva do ensino da evolução como possibilidade de eixo integrador de conteúdos biológicos.

\section{METODOLOGIA}

\section{Seleção das coleções didáticas}

As listas de livros didáticos aprovados pelo Ministério da Educação para serem adotados pelos professores estão disponíveis na página online do Fundo Nacional do Desenvolvimento da Educação (http://www.fnde.gov.br/programas/livro-didatico/guia-do-livro). Dessas listas foram selecionadas três coleções, de acordo com a disponibilidade das obras para empréstimos ou aquisição, priorizando-se as mais recentes. Duas obras selecionadas pertenciam à lista divulgada em 2008 e uma à lista de 2011. As coleções foram designadas no decorrer do trabalho como coleção A, B e C.

\section{Seleção dos dados}

Os capítulos usados para a análise foram os referentes ao filo Chordata (Cordados), tendo em vista que o tema oferece maior possibilidade para explicações evolutivas, como as explicações sobre a origem e a diversificação dos grupos. Foram analisados também os capítulos referentes ao conteúdo de evolução, já que é imprescindível saber como os autores tratam esse assunto para analisarmos de que maneira ele a insere como eixo integrador nos demais conteúdos.

\section{Análise de conteúdo}

Para análise dos capítulos selecionados tomou-se como referência a Análise de Conteúdo segundo Bardin (2004). A interpretação do texto, entendida como a significação concedida a características enunciadas, é feita a partir de inferências. Elas deduzem ideias que excedem o conteúdo explícito nas mensagens e que podem estar agregadas a outros elementos (FRANCO, 2005; DOMINGUINI e ORTIGARA, 2010). Nesse caso, essas ideias seriam as explicações dos fenômenos biológicos baseados em causas próximas ou últimas. As inferências são originadas a partir de qualquer componente da comunicação: emissor, receptor, características da mensagem (FRANCO, 2005). Com isso, o analista, ao manipular as mensagens, pode inferir, de forma coerente, conhecimentos e mensagens que extrapolem o conteúdo explícito e que podem estar associados a outros elementos (BARDIN, 2004; FRANCO, 2005).

As categorias de análise do conteúdo de cordados: A definição das unidades 
de análise se deu em função da identificação de sequências, a chamada análise sequencial, de acordo com a proposição de Bardin (2004). Segundo a autora, é possível distinguir novas sequências quando há "mudança de assunto, ou existe a passagem da narração à descrição, à explicação, etc.” (p. 169). É possível fazer tal distinção a partir de rupturas presentes no texto as quais o autor identifica através de palavras que mostram a transição de um assunto para outro, por exemplo.

Nesse sentido, a troca da abordagem fisiológica pela evolutiva, e vice-versa, indica uma ruptura na sequência do tema abordado. Essas rupturas mostram se o autor usa a evolução e/ou a fisiologia para explicar ou descrever os fenômenos biológicos. Dependendo da existência ou não das rupturas e de sua frequência, o autor pode usar a evolução em toda a sua obra ou limitá-la apenas a capítulos específicos.

Para essa análise, foi feita a leitura dos capítulos que abordavam o filo dos cordados com o intuito de identificar e classificar as unidades de registro ${ }^{1}$ (BARDIN, 2004; FRANCO, 2005) presentes no texto. As unidades de registros foram definidas como: descrição, explicação, argumentação, diálogo e narração. A definição das unidades de registro nem sempre foi simples, por isso optou-se pelo nível semântico (temático) (BARDIN, 2004) para delimitá-las dentro do texto.

A classificação das unidades de registro segue uma proposta de Bronckart (1999) inspirado em outros trabalhos. Segundo essa proposta, na infraestrutura textual se distingue um nível de organização sequencial ou linear do conteúdo temático. Bronckart se apoia nos trabalhos de Adam (1992 apud BRONCKART, 1999) que apresenta cinco tipos básicos de sequências: a narrativa, a descritiva, a argumentativa, a explicativa e a dialogal.

Essas sequências podem ser combinadas em um texto, em várias modalidades e é da diversidade das sequências e da diversidade de suas modalidades de articulação que decorre a heterogeneidade composicional da maioria dos textos. (Bronckart, 1999, p. 219)

Ainda segundo Bronckart (1999), na sequência narrativa, os eventos possuem uma ordem cronológica e são arranjados de modo a formar uma história com início, meio e fim. A sequência descritiva é composta por frases que se assentam em uma ordem hierárquica ou vertical, mas não formam uma ordem linear obrigatória. Na sequência argumentativa há um raciocínio lógico que gera uma série de argumentos e acarreta uma conclusão. A explicativa aponta causas e/ou razões para uma afirmação inicial. A sequência dialogal é uma conversação entre interlocutores que forma um texto coerente. Obviamente que a distinção entre as sequências nem sempre é clara. E, às vezes, algumas sequências podem estar articuladas ou inseridas em outras sequências, como a descritiva que pode estar presente dentro da narração ou da explicação. No entanto, essas sequências arraigadas em outras se portam como sequências secundárias ou relacionadas a essas sequências principais.

Nas unidades de registro dos textos selecionados foram detectadas pala- 
vras e/ou expressões que se referiam a processos evolutivos ou a conceitos trabalhados em evolução, para que estes fossem classificados na categoria das causas últimas, de acordo com Mayr. O mesmo foi feito para palavras e/ou expressões que remetessem à fisiologia, ou seja, das causas próximas dos fenômenos. Essas categorias advindas da estrutura conceitual da biologia de Mayr correspondem às unidades de contexto (BARDIN, 2004; FRANCO, 2005). Segundo esses autores, as unidades de contexto devem ser definidas e utilizadas como base para o entendimento da classificação da unidade de registro (Tabela 1).

Tabela 1: Critérios de detecção das unidades de contexto (sentido fisiológico ou evolutivo) nas unidades de registros (descriç̃ões, explicações, argumentações, diálogos ou narrações) presentes nos livros didáticos analisados:

\begin{tabular}{|c|c|}
\hline $\begin{array}{l}\text { Sentido Fisiológico está presente quando o } \\
\text { (s) autor (es): }\end{array}$ & $\begin{array}{l}\text { Sentido Evolotivo está presente quando o (s) } \\
\text { autor (es): }\end{array}$ \\
\hline $\begin{array}{c}\text { Explica }(m) \text { para que serve uma determina } \\
\text { estutura }\end{array}$ & $\begin{array}{l}\text { Descreve }(m) \text { característica, fenômenos ou } \\
\text { processos, porém utilizando palavras que } \\
\text { remetem à evolução, por exemplo: Adaptação, } \\
\text { Novidade Evolutiva, Primitivo, Ancestral, } \\
\text { Surgimento, Aquisição }\end{array}$ \\
\hline $\begin{array}{l}\text { Compara }(\mathrm{m}) \text { certas característica } \\
\text { morfológicas e fisiológicas entre os grupos }\end{array}$ & $\begin{array}{c}\text { Compara }(m) \text { as característica dos seres vivos } \\
\text { apresentando quais são as ancestrais e as } \\
\text { derivadas }\end{array}$ \\
\hline Descreve $(m)$ as partes do corpo & $\begin{array}{c}\text { Explica }(m) \text { ou narra }(m) \text { o surgimento de } \\
\text { determinada característica ou grupo de } \\
\text { animais }\end{array}$ \\
\hline $\begin{array}{l}\text { Descreve }(\mathrm{m}) \text { os processos / fenômenos e } \\
\text { como eles acontecem }\end{array}$ & \\
\hline
\end{tabular}

\section{Resultados e discussão}

O conteúdo de cordados está assim apresentado nas três coleções analisadas: Coleção A: São 54 páginas divididas em seis capítulos, dentro da unidade sobre o reino animal. Coleção B: São 31 páginas que compõem um único capítulo sobre cordados. Coleção C: São 47 páginas dedicadas ao conteúdo de cordados que compõem um único capítulo, como na Coleção B.

\section{Sentido fisiológico}

Considerando-se as unidades de registros, apenas a descrição e a explicação foram empregadas nos textos analisados para expressar ideias fisiológicas, sendo que as descrições foram muito mais frequentes do que as explicações.

Em todas as coleções, grande parte do conteúdo está concentrada em descrições fisiológicas, com uso de vírgulas ou pontos entre citações de características dos cordados. Além disso, há interrupções repentinas no assunto como nos exemplos abaixo em que os autores da Coleção A, depois de descreverem o tegumento dos répteis, comentam sobre a respiração, e o autor da 
Coleção B que fala da estrutura óssea e da respiração no mesmo parágrafo:

[...] A pele é seca, sem glândulas e completamente impermeável, com camada externa, de escamas ou placas córneas, formada por uma proteína, a queratina. A respiração é exclusivamente pulmonar, mesmo nas espécies aquáticas, [...]. (Coleção A)

Os ciclóstomos são destituídos de mandíbulas e de vértebras típicas. A caixa craniana e as vértebras são cartilaginosas. Apresentam respiração branquial, possuindo de seis a catorze pares de brânquias. (Coleção B)

As explicações, presentes em todas as coleções, são poucas quando comparadas às descrições e elas estão situadas após a introdução de algum conceito, sendo usadas para elucidar o funcionamento ou a importância de uma estrutura ou um hábito do animal estudado. Porém, na Coleção B, elas são muito mais escassas quando comparadas às descrições ou às explicações presentes nas coleções A e C.

[...] O significado biológico da viviparidade nessas espécies é que ela dá às fêmeas melhores condições de controlar a temperatura dos embriões, reduzindo o seu tempo de desenvolvimento [...]. (Coleção A)

[...] Em virtude da carência de queratina, a pele é relativamente permeável. Assim, esses animais [os anfíbios] têm pouca defesa contra a perda de água para o meio externo e vivem geralmente restritos a ambientes úmidos. (Coleção B)

Os olhos dos anfíbios são bem desenvolvidos, mas só conseguem enxergar objetos em movimento. Essa é a razão pela qual eles se alimentam apenas de animais vivos. (Coleção C)

\section{Sentido evolutivo}

Foram encontradas em todas as coleções três unidades de registro que expressavam sentido evolutivo: descrições, explicações e narrações, sendo as descrições mais frequentes, com características estruturais semelhantes às das descrições fisiológicas. O diálogo não foi encontrado em nenhuma coleção e a argumentação apareceu uma única vez, apenas na Coleção C.

A principal diferença entre as descrições evolutivas e as fisiológicas é que nas unidades de registro evolutivas há presença de expressões, de palavras ou de conceitos ligados à evolução biológica como: adaptação, novidade evolutiva, primitivo, ancestral, surgimento, aquisição.

As nove mil espécies de aves existentes formam um grupo de anatomia muito uniforme, revelando uma excepcional adaptação ao voo. De todas as adaptações, a mais marcante é o esqueleto [...]. (Coleção A) [Grifos nossos]

Animais aquáticos, os peixes têm o corpo geralmente fusiforme e dotado de nadadeiras, o que constitui uma adaptação para a natação. (Coleção B) [Grifos nossos]

A pele dos mamíferos apresenta uma apomorfia, isto é, uma novidade evolutiva típica 
do grupo: a presença de pelos. (Coleção C) [Grifos nossos]

As explicações evolutivas também estão em menor número quando comparadas às descrições e não estão necessariamente após a introdução de um conceito como ocorria nas explicações fisiológicas.

É a notável adaptação à vida aquática, no entanto, o que mais marca o grupo. Para locomoção nesse meio, esses grandes nadadores têm alto gasto energético, em parte reduzido por causa das adaptações relacionadas à forma hidrodinâmica do corpo e às glândulas da pele, que lhes permitem vencer melhor a resistência da água [...]. (Coleção A) [Grifos nossos]

Os peixes são gnatostomados, isto é, apresentam mandíbulas. A presença de mandíbulas contribui para a captura de presas, favorecendo a aquisição de porções relativamente grandes de alimento conferindo vantagens adaptativas em relação a predadores competidores menores [...]. (Coleção B) [Grifos nossos]

A presença de nadadeiras pares e de uma nadadeira caudal eficiente é uma importante aquisição evolutiva desses peixes em relação aos seus ancestrais agnatos. Aliadas a uma musculatura poderosa e uma pele especialmente adaptada para oferecer pequena resistência na água, as nadadeiras dos condrictes permitem que estes animais nadem com muita rapidez. (Coleção C) [Grifos nossos]

As narrações evolutivas estiveram presentes em todas as coleções e se referem apenas à origem, à diversificação ou à dispersão dos cordados, como mostra os exemplos a seguir:

Os primeiros cordados surgiram na Terra há cerca de 500 milhões de anos (era Paleozoica). Desde então, esses animais se expandiram de forma extraordinária, partindo do meio aquático e ocupando os mais diversos ambientes terrestres até a última conquista, a capacidade de voo. (Coleção A) [Grifos nossos]

Os anfíbios são vertebrados terrestres que provavelmente surgiram na Terra no período Devoriano, há cerca de 350 milhões de anos, a partir de peixes pulmonados [...]. (Coleção B) [Grifos nossos]

Acredita-se que, no passado, os marsupiais viviam em diversos continentes e eram muito numerosos, mas a competição com os mamíferos placentários determinou a extinção da maioria das espécies. O continente australiano, que apresenta uma grande quantidade de marsupiais, não foi invadido pelos placentários por estar separado dos demais. Na América do Sul também existiu uma fauna diversificada de marsupiais, em grande parte extinta pela competição com placentários. Um dos poucos sobreviventes foi o gambá, que se expandiu em direção inversa e invadiu a América do Norte. (Coleção C) [Grifos nossos]

A única argumentação presente nas coleções analisadas foi encontrada na Coleção $\mathrm{C}$, relacionada à controvérsia em torno da necessidade de uma revisão na taxonomia dos répteis e aves.

As penas estão atualmente presentes apenas nas aves, mas não constituem uma ca- 
racterística exclusiva do grupo, pois elas também faziam parte do corpo de répteis hoje extintos. Esse é um dos argumentos utilizados por alguns sistematas da escola cladista para sugerir a colocação de aves e répteis em um mesmo grupo taxonômico. (Coleção C) [Grifos nossos]

\section{Evolução nas coleções}

$\mathrm{Na}$ Coleção A, o tema evolução é apresentado no terceiro volume e compreende seis capítulos em uma unidade com 99 páginas. Contudo, há elementos e termos evolutivos dispersos nos outros volumes. No primeiro volume, a evolução aparece de forma superficial no Capítulo 1, que trata das características da vida e dos seres vivos, onde os autores afirmam que uma das características dos seres vivos é a capacidade de evoluir. Em outro ponto do livro, no Capítulo 17, que aborda o conteúdo da origem da vida, o autor traz a evolução dos primeiros seres vivos a partir de certas moléculas e de algumas organelas presentes nos mesmos. Já no segundo volume, os conteúdos evolutivos assumem uma importância maior, principalmente na primeira unidade sobre biodiversidade e classificação. No decorrer do volume, eles são abordados dentro de alguns capítulos que tratam de seres vivos como, por exemplo, as plantas e os vertebrados.

Há poucos apêndices de capítulos, fora do corpo principal do texto, que trazem algo relacionado à evolução. Aqueles que o apresentam estão dentro dos capítulos que discutem algum tema evolutivo, como, por exemplo, no conteúdo de origem da vida no primeiro volume, ou no conteúdo sobre seres vivos e classificação no segundo volume, ou na unidade de evolução no terceiro volume.

O conteúdo de evolução na Coleção B é apresentado no terceiro volume abrangendo a Unidade 3 com 35 páginas e três capítulos. O assunto é tratado de forma simples, sem aprofundamento e algumas vezes o autor apenas conceitua determinado termo, como, por exemplo, a seleção natural e o fluxo gênico. Enquanto nas demais coleções existem breves explicações de alguns termos evolutivos que serão usados no decorrer dos livros no início do primeiro e segundo volumes, na Coleção B, isso não ocorre. No volume 1 há o Capítulo 7 sobre a origem da vida que narra como possivelmente surgiram e evoluíram as primeiras formas de vida na Terra. Não há tópicos ou capítulos relacionados à evolução no segundo volume nem há cladogramas ou filogenias para exemplificar a evolução dos grupos de seres vivos.

Os apêndices e textos para leitura complementar aos conteúdos são escassos de conteúdo evolutivo, exceto na parte de citologia no Volume 1, na qual quadros explicativos narram, fora do texto principal, a provável origem das células eucarióticas, de suas organelas e da fotossíntese. No Volume 2, a maior parte do conteúdo evolutivo está no capítulo sobre cordados. Mesmo assim, a maioria dos textos visa apenas a curiosidades, e não à aplicação prática dos conteúdos.

$\mathrm{Na}$ Coleção C, assim como nas demais, a unidade referente à evolução biológica está no terceiro volume, contendo três capítulos, totalizando 77 páginas. Além disso, no início dos outros volumes da coleção existem elementos dentro dos capítulos que abordam certos temas evolutivos. No primeiro volume, quando 
os autores caracterizam os seres vivos, há um tópico conceituando variabilidade genética, seleção natural e adaptação, funcionando como uma base para melhorar a compreensão dos capítulos seguintes. Além disso, antes de iniciar o conteúdo de citologia, no Capítulo 2, os autores tratam da evolução e diversificação da vida, falando sobre a origem da célula eucariótica, hipótese endossimbiótica e a origem da multicelularidade. Já no segundo volume, que trata basicamente dos seres vivos e da fisiologia, a evolução está presente no Capítulo 1, que aborda a sistemática e a taxonomia, um tópico longo que esclarece como a teoria evolucionista explica a formação de novas espécies. Além disso, aparece também um tópico relacionando a classificação biológica com o parentesco evolutivo. Ainda no segundo volume, em alguns capítulos que abordam alguns grupos de seres vivos (bactérias, plantas, anfíbios, répteis, aves e mamíferos), existem tópicos que comentam a origem evolutiva dos grupos e o parentesco entre eles.

O único texto fora do corpo principal que contém uma abordagem evolutiva foi o encontrado na unidade sobre evolução, no terceiro volume, que trata sobre o conceito de raças e da inexistência delas na espécie humana, provendo alguns ideais que são recomendadas pelo PNLD, como a formação cidadã dos alunos e os desestímulos aos preconceitos.

\section{Análise sequencial}

As rupturas de sentidos usadas para a análise sequencial foram computadas por grupo taxonômico para cada uma das coleções (Tabela 2). Um maior número de rupturas, isto é, de trocas do sentido evolutivo pelo fisiológico e vice-versa, representa se o autor usa a evolução em toda a obra. Como pôde ser observado, o capítulo sobre os anfíbios apresentou o menor número de rupturas, e os capítulos de répteis, aves e mamíferos tiveram o maior.

Tabela 2: Número de rupturas encontradas nos conteúdos de cordados nas três coleções analisadas.

\begin{tabular}{|c|c|c|c|c|c|c|c|}
\hline \multicolumn{8}{|c|}{ Número de Rupturas } \\
\hline $\begin{array}{c}\text { Coleções } \\
\text { Analisadas }\end{array}$ & Protocordados & $\begin{array}{c}\text { Cidóstomos e } \\
\text { Peixes }\end{array}$ & Anfíbios & Répteis & Aves & Mamíferos & Total \\
\hline A & 9 & 8 & 5 & 9 & 5 & 16 & 52 \\
\hline B & 3 & 4 & 1 & 7 & 7 & 4 & 26 \\
\hline C & 6 & 10 & 1 & 15 & 13 & 13 & 58 \\
\hline
\end{tabular}

Algo notável é que em muitos casos os textos que narram a origem evolutiva de um grupo ou uma estrutura estavam condicionados a quadros explicativos no fim dos capítulos ou como curiosidades entre os tópicos. Na maioria das vezes, eles não estavam referenciados no corpo do texto, mas estavam soltos dentro dos capítulos. Por sua ausência no texto principal, esses textos foram desconsiderados na contagem das rupturas.

O uso da evolução não ocorreu de forma igualitária no conteúdo de cor- 
dados. O conteúdo de mamíferos teve mais rupturas, junto com os conteúdos de répteis e aves. Nesses capítulos os autores gastaram mais tempo explicando suas principais adaptações, sejam elas relacionadas à alimentação ou ao habitat, inserindo, assim, o sentido evolutivo mais vezes do que nos demais capítulos.

O fato de os autores gastarem mais tempo com os répteis, as aves e os mamíferos pode ser devido ao fato de esses animais estarem mais presentes no cotidiano dos alunos como animais de estimação ou livres no ambiente em que os alunos frequentam. Outra possibilidade é devido a uma visão antropocêntrica dos conteúdos de ciências (AMARAL, 2006), já que esses grupos são os mais próximos filogeneticamente aos humanos. Em alguns trechos, os autores empregam uma visão antropocêntrica para comentar a importância de determinados animais, mascarando o papel ecológico das espécies no meio ambiente e enfatizando apenas os recursos adquiridos pelo homem a partir da exploração desses animais:

Igualmente múltiplas são as utilidades dos peixes para os seres humanos [...]. Mesmo o temido tubarão é mais útil aos interesses humanos do que alguns pensam: além de carne, suas nadadeiras constituem um ingrediente básico na preparação de sopas bastante apreciadas por muitas pessoas. As nadadeiras, ainda, são empregadas na indústria de fibras ópticas para computadores e na fabricação de lixas, adubos e colas. E, depois de curtidas, a pele do tubarão pode ser usada em encadernação de requintes e também em artesanatos. Além disso, o fígado fornece um óleo muito rico em vitamina A. (Coleção B)

De maneira geral, as coleções A e C utilizaram mais o sentido evolutivo para apresentar o conteúdo referente a cordados, pois proporcionaram mais rupturas. A Coleção B, se compararmos às três coleções, tem o menor potencial para se trabalhar o conteúdo a partir dessa abordagem evolucionista já que utilizou poucas rupturas. A Coleção A trouxe algumas vezes no decorrer do livro a evolução de forma confusa, podendo proporcionar interpretações de duplo sentido em alguns momentos, diferente da Coleção $C$ que conseguiu passar as ideias de forma mais clara. Contudo, a Coleção C é muito detalhista no conteúdo fisiológico e por isso ela é a mais volumosa. Comparando proporcionalmente o número de rupturas pelo tamanho do corpo do texto, a Coleção A seria a que mais emprega o sentido evolutivo. Nos exemplos abaixo é mostrado como as três coleções mostram de formas diversas um mesmo fenômeno biológico.

[...] Nos peixes, essas fendas adquirem função respiratória, surgindo aí as brânquias. Embora se formem na fase embrionária de todos os cordados, as fendas faríngeas não persistem na fase adulta [...]. (Coleção A) [Grifos nossos]

[...] [As fendas branquiais] se prestam à filtração de alimentos ou à respiração, as fendas branquiais permanecem nos protocordados e nos peixes adultos; nos outros grupos, estão presentes apenas nos embriões, fechando-se no decorrer do desenvolvimento. (Coleção B)

[...] Nos cordados aquáticos, o tecido que reveste as traves entre as fendas faringianas desenvolve-se e origina as brânquias; nos cordados terrestres, as fendas faringianas se 
fecham e desaparecem no decorrer do desenvolvimento embrionário. (Coleção C)

O sentido evolutivo não fica claro no exemplo retirado da Coleção A. Isso acontece porque o uso da linguagem científica, carregada de gerúndio e orações subordinadas para sintetizar ideias e para ajudar na estética do texto, dificulta a compreensão (FANG, 2006). Na sentença transparece que as brânquias surgiram apenas pelo fato de as fendas faríngeas trocarem de função, sem passar por modificações morfológicas ou por uma passagem de tempo, isto é, sem evoluir.

Os condríctios têm fecundação interna, pois os espermatozoides são passados para as fêmeas através do clásper. (Coleção A)

[Conteúdo apresentado em uma tabela fora do corpo do texto] Fecundação de condrictes: Interna e sem larvas; nadadeiras pélvicas transformadas em órgãos copuladores denominados clásper. (Coleção B)

Os condrictes têm reprodução sexuada e são dioicos, com fecundação interna. Machos de tubarões têm um par de cláspers, órgãos copuladores formados por diferenciações das nadadeiras pélvicas. Com essas estruturas, eles introduzem esperma na cloaca da fêmea. (Coleção C)

O segundo exemplo evidencia a diferença de detalhamento entre as coleções ao descrever um mesmo fenômeno. Enquanto as coleções A e C trazem a explicação no corpo do texto, a última com mais detalhes, a Coleção B só aborda o assunto em uma tabela alusiva às diferenças entres os peixes cartilaginosos e os peixes ósseos.

Uma característica compartilhada pelas três coleções analisadas é o uso excessivo das descrições e o pouco uso da narração, explicação e argumentação. A descrição demasiada nos livros estimula mais a memorização de um conjunto de dados e de fatos do que explica as causas dos fenômenos ou argumenta sobre a relevância dos dados apresentados. Dados soltos não possuem uma coerência se não são acompanhados por explicações e argumentações para que tragam significação a eles (POZO e GÓMEZ CRESPO, 2009).

[...] uma coisa é ter um dado, conhecer algo como fato, e outra é dar-lhe sentido ou significado. Compreender um dado requer utilizar conceitos, ou seja, relacioná-los dentro de uma rede de significados que explique por que ocorrem e que consequências eles têm. (POZO \& GÓMEZ CRESPO, 2009, p. 78)

Dessa forma, por exemplo, falar que os vertebrados têm sistema circulatório fechado ou que o coração dos anfíbios possui três câmaras e não explicar quais as consequências adaptativas dessas características para a vida dos seres vivos apenas incentiva a reprodução e memorização de dados. Isso não auxilia no desenvolvimento das funções mentais que possibilitam a inserção dos estudantes na linguagem científica.

É claro que os alunos precisam aprender dados no ensino de qualquer ciência, porém a transmissão de dados não deveria constituir um fim principal da educação 
cientifica, que deveria estar dirigida, na verdade, a dar sentido ao mundo que nos rodeia, a compreender as leis e os princípios que o regem (POZO e GÓMEZ CRESPO, 2009, p. 80). E os livros didáticos que prezam excessivamente pelas descrições e abandonam o uso de explicações e de argumentações amparam, dessa forma, um ensino da ciência como transmissão de fatos, e não como um processo de construção de conceitos.

As sequências argumentativas, praticamente ausentes nos livros didáticos analisados, são valiosas em uma aula de ciências, pois é uma das principais formas de discussão na comunidade científica (CAPECCHI e CARVALHO, 2000) e deveriam estar mais presentes nos livros e, consequentemente, nas salas de aula. A ciência trabalha com a lógica dos argumentos, e o desenvolvimento do pensamento científico é ligado ao pensamento argumentativo (YORE et al., 2004). Os cientistas precisam fazer argumentos coerentes e organizados para convencer a comunidade científica de que suas teorias estão corretas e para evitar inconsistências e contradições (FANG, 2006). Além disso, a argumentação também pode ser usada como uma maneira de aproximação entre o pensamento científico e o cotidiano (KUHN, 1993), algo positivo tendo em vista as concepções alternativas advindas do cotidiano que dificultam a aprendizagem em ciências (POZO e GÓMEZ CRESPO, 2009).

Ribeiro e Martins (2007) indicaram a possibilidade de se usar narrativas no ensino de Ciências Naturais, apresentando-as como uma alternativa pedagógica disponível ao professor em sala de aula, algo pouco presente nos livros didáticos analisados. Vários autores também já fizeram propostas para incluir e avaliar o uso de narrativas como recurso didático em sala de aula, não apenas nas aulas de línguas (MILLAR e OSBORNE, 1998 apud RIBEIRO e MARTINS, 2007; NORRIS et al., 2005).

Norris et al. (2005) consideram a narrativa importante instrumento para a educação científica por promover a memorização, a compreensão e aumentar o interesse dos alunos. Ela seria ideal também para contextualização de conteúdos e para a interdisciplinaridade que é um dos princípios estruturadores do currículo, funcionando como uma ponte que propicia o diálogo entre os vários conteúdos (RIBEIRO e MARTINS, 2007).

Mais especificamente, no ensino de ciências, narrativas de episódios que se relacionam à História da Ciência permitem resgatar um diálogo existente, mas quase sempre ignorado, entre a atividade científica e outras atividades humanas. (RIBEIRO e MARTINS, 2007, p. 294)

A abordagem da história da ciência raramente aparece nos livros de biologia adotados no país. Os alunos ficam carentes de contextualização histórica para o entendimento de como os conceitos foram se desenvolvendo ao longo do tempo (RIBEIRO e MARTINS, 2007).

Mortimer et al. (1998) afirmam que a narração é a que mais se aproxima da linguagem do cotidiano, com sequências lineares de episódios, ao contrário 
da linguagem científica que prega a nominalização, dando mais importância à forma estrutural das frases do que ao padrão linear dos eventos (FANG, 2006). Com a nominalização, a linguagem científica supre o nome dos processos que são expressos normalmente por verbos e usa grupos nominais (HALLIDAY e MARTIN, 1993 apud FANG, 2006). Isso pode ser mais uma barreira para o aluno, habituado a assinalar seres e coisas por nomes e processos por verbos (MORTIMER et al., 1998).

A educação científica deveria fazer um uso muito maior das narrativas (MILLAR e OSBORNE, 1998 apud RIBEIRO e MARTINS, 2007), e os currículos de Ciências deveriam ser estruturados tomando-se por base um conjunto de estórias que explicam e descrevem como o mundo funciona (RIBEIRO e MARTINS, 2007). O uso mais frequente de narrativas nos livros didáticos pode tornar esse processo mais fácil, já que estudantes têm maior habilidade em lidar e em entender esse tipo de estrutura textual (FREGUGLIA, 2009).

Contudo, os alunos têm que ser capazes de ler e de escrever na linguagem científica para se comunicar efetivamente em ciência (FANG, 2006). De acordo com Mortimer et al. (1998), não há como separar a aprendizagem de ciência e a aprendizagem da linguagem científica. Norris \& Phillips (2003) argumentam que o desenvolvimento da ciência ocidental é condicionado à escrita científica e, sem o contato com ela, o aprendizado dos estudantes estará limitado. Por isso, é necessário um uso judicioso de tais textos narrativos, o suficiente para trazer benefícios, como o interesse dos alunos, mas não em excesso, para que a linguagem científica seja pouco abordada (FANG, 2006). A ciência desenvolveu sua linguagem própria, e os alunos devem ter experiência com ela. Expô-los a linguagem da ciência na escola é essencial para essa experiência (FANG, 2006).

Além disso, um livro didático que apresente muita narração e argumentação pode encontrar alguns obstáculos. O uso dessas sequências e a agregação de ideias evolutivas a todos os conteúdos da biologia transformariam o produto final inviável do ponto de vista econômico, pois os livros ficariam volumosos, aumentando os custos para as editoras, para os alunos e para o governo.

Dessa forma, a presença de expressões, de palavras ou de conceitos ligados à evolução biológica, tais como adaptação, ancestral, surgimento e outros, produz sínteses que podem ser úteis no contexto de produção de livros didáticos. A intenção de colocar esses termos que remetem à evolução resume de forma hábil toda a explicação evolutiva por trás do fenômeno ou da característica. Mesmo que à primeira vista os exemplos não apresentem um sentido evolutivo claro, pois trazem ideias voltadas à anatomia e morfologia, a presença de termos que remetem à evolução pode propiciar a produção de outro sentido nas frases tornando a evolução o foco principal.

Para que se tenha uma ideia da importância dos termos que remetem à evolução para construção do sentido evolutivo, vamos a um exemplo. Se esses termos que envolvem as causas últimas fossem retirados das sequências, o sentido da unidade mudaria para o contexto fisiológico: 
[...] junto a ela [notocorda] há pequenas peças cartilaginosas - as vértebras primitivas dispostas como arcos incompletos ao redor da medula espinhal [...]. (Coleção A) [Grifos nossos] Sentido evolutivo presente na obra.

[...] junto a ela [notocorda] há pequenas peças cartilaginosas - as vértebras - dispostas como arcos incompletos ao redor da medula espinhal [...]. (Coleção A) Sentido fisiológico, sem a palavra 'primitivas'.

O exemplo acima retirado da Coleção A explica que as peças cartilaginosas são, na verdade, estruturas com características primitivas presentes nas lampreias atuais e que também deveriam estar presentes no ancestral comum das lampreias e dos peixes. Entretanto, se a palavra primitivas for omitida, o exemplo traz um contexto fisiológico e não evolutivo, apresentando como sinônimos "peças cartilaginosas das lampreias" e "vértebras".

No entanto, é necessário cautela no uso dos termos científicos. Nas coleções há um exagero no uso desses termos que complica o entendimento dos alunos. Esses termos são vitais por representar exatamente um conhecimento especializado da ciência. Muitas dessas palavras, apesar de difícil adoção pelos alunos, não podem ser traduzidas na linguagem do cotidiano sem perda de significado e de exatidão técnica (HALLIDAY e MARTIN, 1993 apud FANG, 2006). Esses vocábulos são os alvos do ensino, devem ser elucidados regularmente, inclusive em glossários. Entretanto, segundo FANG (2006), "um aumento significativo das dificuldades dos alunos pode surgir quando há uma concentração de termos técnicos na mesma frase" (p. 494). Segundo esse autor, quando mais de um terço da frase corresponde a vocábulos científicos, a linguagem fica mais densa de informação e pode causar problemas ao entendimento dos alunos. Orações ou períodos com essas características foram encontrados em todas as coleções, tanto no contexto evolutivo quanto no fisiológico.

[Primatas] são mamíferos de grande desenvolvimento encefálico, pernas longas, dedos com unhas, órbitas voltadas para frente e dentes molares com tubérculos adaptados a alimentação onívora. (Coleção A) [Grifos nossos]

Apesar do uso de termos evolutivos ao longo de toda a coleção, a unidade destinada à abordagem desse assunto está presente no terceiro volume em todas as coleções. Mesmo que alguns capítulos iniciais dos outros volumes nas coleções A e C conceituem alguns desses termos, isso pode não ser suficiente para o aluno deter o conhecimento evolutivo necessário para compreender esses termos em sua totalidade, podendo acarretar problemas na interpretação dos textos didáticos. Além disso, os termos que remetem à evolução, apesar de ser uma forma hábil de abordar a evolução em diferentes conteúdos, resumindo narrações históricas em palavras, podem trazer mais prejuízos do que benefícios para os alunos se esses conceitos e palavras não estiverem bem-cimentados. Muitos desses termos estão 
presentes na linguagem cotidiana com um sentido distinto daquele que se pretende no ensino de evolução.

O ensino de evolução e de seus conceitos tem um componente agravante, pois vai de encontro a muitas concepções alternativas enraizadas profundamente e contrárias ao conhecimento científico estabelecido, especialmente as concepções baseadas na visão religiosa (ALTERS e NELSON, 2002). As concepções alternativas teriam três origens possíveis, segundo Pozo \& Gómez Crespo (2009): a origem sensorial, advinda de concepções espontâneas dos alunos; a origem cultural, onde as ideias de alguns grupos sociais seriam refletidas na compreensão dos alunos; e a origem escolar, na qual alguns conceitos aprendidos na sala de aula levam a interpretações erradas, e os alunos criam por consequência sistemas análogos de conhecimentos, mas diferentes do conhecimento científico.

Além de o conteúdo de evolução ser altamente complexo, algumas construções dos livros didáticos podem trazer mais dificuldades a essa tarefa árdua. Alguns termos que remetem à evolução nos livros didáticos foram usados em algum momento também no sentido fisiológico dentro do conteúdo dos cordados, outros termos possuem significados diversos na linguagem científica quando comparada com a linguagem do senso comum. E ainda houve termos que eram incertos quanto ao sentido que apresentavam, não podendo definir se eles enfatizavam a fisiologia ou a evolução em seu contexto.

Termos que remetem à evolucão sendo usados em um contexto fisiológico: Alguns termos utilizados para classificar as unidades em sentido evolutivo foram empregados com diferentes significados pelos autores das coleções A e C. As mesmas palavras que foram expressas como causas últimas em outro ponto do conteúdo foram usadas para ajudar na descrição ou na explicação de conteúdos voltados para as causas próximas.

Os anfíbios constituem uma classe muito provavelmente originada de peixes aparentados aos dipnoicos (peixes pulmonados) atuais [...]. (Coleção A) [Grifos nossos] Sentido evolutivo.

[...] Os biólogos acreditam que as larvas dos urocordados sejam muito parecidas com o organismo ancestral que originou todos os cordados. (Coleção C) [Grifos nossos] Sentido evolutivo.

As penas são estruturas mortas, de queratina, originadas a partir de papilas vivas da derme [...]. (Coleção A) [Grifos nossos] Sentido fisiológico, ontogenia.

As brânquias são órgãos ricamente vascularizados que se originam do revestimento dos arcos entre as fendas faringianas do embrião [...]. (Coleção C) [Grifos nossos] Sentido fisiológico, ontogenia.

Nos dois primeiros exemplos, os termos destacados são derivados do verbo "originar" e apresentam um sentido evolutivo, descrevendo que certos grupos 
animais são originados de outros. Já nos dois últimos exemplos, as palavras com o mesmo radical de "originar" expõem um sentido fisiológico, de que certas estruturas apareceram por processos ontológicos e não evolutivos. A mesma coisa acontece nos exemplos abaixo com o termo "surgir".

[...] Existem evidências de que o esplancnocrânio [mandíbula] surgiu, durante a evolução dos craniados, a partir da transformação gradual dos primitivos arcos (ou traves) da faringe, os arcos branquiais. (Coleção C) [Grifos nossos] Sentido evolutivo.

[...] Nesse muito remoto passado da história da vida da Terra, surgiram diferentes linhas evolutivas dos chamados dinossauros [...]. (Coleção A) [Grifos nossos] Sentido evolutivo.

Nas lampreias, a notocorda que surge durante o desenvolvimento embrionário perdura por toda a vida [...]. (Coleção C) [Grifos nossos] Sentido fisiológico.

[...] [Sobre a metamorfose dos anfíbios] Em seguida amplia-se a boca, atrofiam-se as brânquias, surgem as pernas anteriores, menores, [...]. (Coleção A) [Grifos nossos] Sentido fisiológico, ontogenia.

Como na Coleção B, diferente das coleções A e C, houve pouco uso das palavras que remetem à evolução nos conteúdos, esses casos de ambiguidade raramente apareceram.

Palavras do cotidiano com significados e/ ou usos distintos na linguagem cientifica: Fang (2006) em seu estudo sobre a leitura científica apontou vários complicadores para a compreensão da linguagem científica pelos alunos do Ensino Fundamental. Entre eles está o uso de termos do cotidiano que apresentam significados distintos quando utilizados no meio científico. Isso pode fazer com que os alunos tenham um pensamento equivocado a respeito da real abordagem trazida pelo texto. Esse complicador foi encontrado nas coleções A e C:

São os peixes mais antigos [Os condrictes], que apresentam um esqueleto completamente cartilaginoso [...]. (Coleção A) [Grifos nossos]

[...] Os vertebrados, que apresentam grande diversidade, são representados por várias classes, desde os mais primitivos, ainda sem mandíbulas (lampreias), até os mandibulados (peixes, anfíbios, répteis, aves e mamíferos). (Coleção A) [Grifos nossos]

[...] Actinopterígios considerados mais primitivos, como os esturjões, têm cauda heterocerca semelhante aos condríctes. (Coleção C) [Grifos nossos]

Os agnatos constituem um grupo informal (sem validade taxonômica) que reúne craniados primitivos sem mandíbulas, de corpo cilíndrico alongado e esqueleto cartilaginoso [...]. (Coleção C) [Grifos nossos]

As palavras destacadas nos exemplos têm significados diferentes no senso comum e no meio científico. Elas podem exprimir a ideia de atrasado, arcaico, 
antiquado ou obsoleto. Essa diversidade de sentidos talvez não tenha sido considerada pelos autores, e isso pode dificultar o entendimento da evolução para alguns alunos. Muitos cientistas mais rigorosos defendem o uso de outros termos para representar grupos primitivos/basais e grupos avançados/derivados para evitar esse tipo de problema. Segundo eles, esses termos são conceitos herdados do progressismo aristotélico e não condiz com a escola cladista aceita por muitos atualmente (SANZ, 2005). Os termos ideais seriam grupos "plesiotípicos" e "apotípicos" (SANZ, 2005).

Além disso, na Coleção A, algumas dessas palavras plurais em sentidos manifestam analogias que não são coerentes com o ensino de evolução, como a analogia da escada evolutiva.

[Nos vertebrados] sempre há um encéfalo, com cinco vesículas, das quais o cérebro é a primeira e, nos vertebrados superiores, a mais desenvolvida. (Coleção A) [Grifos nossos]

Palavras não usadas em seu sentido comum, que podem servir a mais de uma função gramatical ou que são usadas metaforicamente criam analogias que, em vez de ajudar na compreensão da evolução, podem trazer dificuldades (BELLINI, 2006). É o caso das analogias em que a evolução aparece como uma escada, um progresso, uma melhoria contínua, em que os seres vivos são apresentados como uma sequência de seres enfileirados onde o antecessor gera o sucessor. Isso ocorre no exemplo acima, no qual há menção aos vertebrados superiores. Esse termo cria a ilusão de que há vertebrados melhores e outros piores (superiores e inferiores).

Termos incertos quanto ao sentido apresentado: Outros termos apresentados pelos autores nas coleções A e B permanecem incertos quanto ao seu sentido, não conseguindo transpor seu verdadeiro significado, pois eles podem se referir tanto à evolução quanto à fisiologia. Nos exemplos abaixo, as palavras destacadas podem representar dois eventos: uma transformação/modificação evolutiva que gerou uma adaptação, ou uma transformação/modificação decorrente da ontogenia dos seres vivos.

[

...] [Nas aves] As extremidades anteriores são transformadas em asas e presas a uma forte cintura escapular, da qual o esterno é o osso mais desenvolvido [...]. (Coleção A) [Grifos nossos]

Quirópteros são os morcegos, com braços modificados em asas [...]. (Coleção A) [Grifos nossos]

[...] Essa superclasse [Tetrapoda] abrange as classes Amphibia, Reptilia, Aves e Mammalia, todas de animais portadores de dois pares de membros; nas aves os membros anteriores são transformados em asas. (Coleção B) [Grifos nossos]

As tartarugas, animais marinhos e dulcícolas, possuem patas transformadas em nadadeiras, que contribuem para a sua locomoção na água. (Coleção B) [Grifos nossos] 
A ambiguidade de sentidos entre as palavras "transformação" e "modificação" pode gerar conflitos de sentidos nos leitores. Com a indefinição da evolução ou da fisiologia atuando nos processos de alteração morfológica, fica confuso para o leitor entender como essas mudanças aconteceram.

Mesmo com todas as dificuldades de interpretação por parte dos alunos, a intenção dos autores dos livros de colocar termos que remetem à evolução em todo o conteúdo de biologia, além do uso de narrativas, pode auxiliar o ensino de evolução nas escolas brasileiras, se mostrando uma alternativa para usar a evolução como um eixo integrador. Além disso, é importante a discussão sobre reformas curriculares que contemplem mudanças na ordem de apresentação dos principais temas da biologia no Ensino Médio, trazendo evolução para séries mais iniciais. Segundo Tidon \& Leowontin (2004), as reformas curriculares em ciências, particularmente na biologia, constituem-se como uma das maneiras decisivas para trazer melhorias ao ensino de evolução no Brasil.

\section{CONCLUSÕES}

Os livros didáticos utilizam a evolução entre os vários conteúdos abordados, mesmo sendo em pouca quantidade. A forma mais comum de sua utilização é a descrição, com o acréscimo de termos evolutivos ou que remetem à evolução. Esses termos sintetizam toda uma história evolutiva em único vocábulo impregnado de sentidos conectados a um conceito evolutivo. Por sua vez, não necessariamente os alunos estarão aptos a perceber tais termos e associá-los à evolução somente pela leitura. Foram encontradas nas coleções características do texto científico que dificultam a compreensão dos conteúdos. Existem, por exemplo, certas palavras que são usadas no cotidiano com significados distintos aos utilizados no meio científico, complicando a compreensão do texto. Além disso, há palavras que são usadas em contextos diferentes, ora se referindo à fisiologia ora à evolução.

As rupturas entre as unidades de contexto demonstraram que, apesar de todos os livros serem aprovados pelo PNLD, existem diferenças significativas entre eles, na forma de abordar a evolução em seu conteúdo, cabendo ao educador a escolha do material mais conveniente para seu trabalho.

Com isso, a abordagem da evolução mostrou-se ainda superficial e fragmentada, não caracterizando o que poderia se considerar uma visão evolutiva integradora no conteúdo de vertebrados. Nessa perspectiva, os livros que mais se aproximaram das diretrizes para o ensino de biologia na perspectiva evolucionista foram as coleções A e C. O ideal seria que as coleções utilizassem mais narrações históricas, argumentações e explicações além de usar com moderação as descrições, pois, na educação científica atual, a aprendizagem que se deseja não se dá apenas pela transmissão de informações.

Nesse sentido, chamamos a atenção para o papel fundamental do profes- 
sor como mediador da leitura realizada pelos alunos e a importância da escolha, por ele, dos textos mais adequados aos propósitos de uma educação científica que vise auxiliar os estudantes a desenvolver formas de dizer e de pensar que se aproximem daquelas utilizadas pela ciência. Este trabalho trouxe contribuições para a análise de textos que circulam pelas salas de aula e que estão à disposição dos professores para a realização dessa tarefa.

\section{AGRADECIMENTOS}

Agradecemos a Edna F. de Cerqueira e a André Cupertino pelos empréstimos dos livros didáticos utilizados durante a construção deste trabalho. Além dos professores Jair de A. Silva e Maria do Carmo P. Batitucci que contribuíram com ideias e sugestões de leituras.

\section{NOTAS}

${ }^{1}$ Segundo esses autores, as unidades de registro são segmentos do conteúdo que servem como base para a categorização e a contagem frequencial. Elas podem estar num nível semântico (tema) ou linguístico (palavra ou frase).

\section{REFERÊNCIAS BIBLIOGRÁFICAS}

ADAM, J.M. Les Textes: types et prototypes. Paris: Nathan, 1992.

ALTERS, B. J.; NELSON, C. E. Perspective: teaching evolution in higher education. Evolution, v. 56, n. 10, p. 1891-1901, 2002.

AMARAL, I. A. Os fundamentos do ensino de Ciências e o livro didático. In: FRACALANZA, H.; MEGID-NETO, J. (orgs.) O livro didático de Ciências no Brasil. 1. ed. Campinas: Editora Komedi, 2006. p. 83-123.

AZEVEDO, M. J. C. Explicações teleológicas no ensino de evolução: um estudo sobre os saberes mobilizados por professores de Biologia. 2007. 100f. Dissertação (Mestrado em Educação) - Programa de Pós-graduação em Educação, Universidade Federal Fluminense, Niterói, 2007.

BARDIN, L. Análise de conteúdo. 3. ed. Lisboa: Edições 70, 2004.

BELLINI, L. M. O conceito de evolução nos livros didáticos: avaliação metodológica. Estudos em Avaliação Educacional, n. 33, p. 7-28, 2006.

BRASIL. Orientacõos curriculares para o ensino médio; volume 2 - Ciências da Natureza, matemática e suas tecnologias. Brasília, Ministério da Educação/Secretaria de Educação Básica, 2006.

. Biologia: catálogo do Programa Nacional do Livro para o Ensino Médio: PNLEM/2009.

Brasília, Fundo Nacional de Desenvolvimento da Educação, Ministério da Educação/Secretaria de Educação Básica, 2008.

. Guia de livros didáticos: PNLD 2012: Biologia. Brasília, Ministério da Educação/Secretaria de Educação Básica, 2011.

BRONCKART, J. P. Sequências e outras formas de planificação. In: - Atividade de linguagem, textos e discursos: por um interacionismo sócio-discursivo. 1. ed. São Paulo: Editora PUC-SP, 1999. p. 217-248. 
BRUNER, J. Atos de significação. Porto Alegre: Artmed, 1997.

CAPECCHI, M. C. V. M.; CARVALHO, A. M. P. Argumentação em uma aula de conhecimento físico com crianças na faixa de oito a dez anos. Investigaçoes no Ensino de Ciências. 2000. Disponível em: <http://www.if.ufrgs.br/public/ensino/vol5/n3/v5_n3_a2.htm>. Acesso em: 20 dez. 2012.

CARNEIRO, M. H. S.; SANTOS, W. L. P.; MÓL, G. S. Livro didático inovador e professores: uma tensão a ser vencida. Ensaio. 2005. Disponível em: < http://www.po

rtal.fae.ufmg.br/seer/index.php/ensaio/article/view/93/142>. Acesso em: 20 dez. 2012.

DOBZHANSKY, T. Nothing in biology makes sense except in the light of evolution. American Biology Teacher, v. 35, n. 3, p. 125-129, 1973.

DOMINGUINI, L.; ORTIGARA, V. Análise de conteúdo como metodologia para seleção de livros didáticos de química. In: ENCONTRO NACIONAL DE ENSINO DE QUÍMICA, 15., 2010. Brasília, Anais dos Encontros Nacionais de Ensino de Química. Disponível em: < http://www. xveneq2010.unb.br/resumos/R0434-2.pdf>. Acesso em: 20 dez. 2012.

EL-HANI, C. N.; ROQUE, N.; ROCHA, P. L. B. Livros didáticos de biologia do ensino médio: resultados do PNLEM/2007. Educação em Revista, v. 27, n. 1, p. 211-240, 2011.

FANG, Z. The language demands of science reading in middle school. Internacional Journal of Science Education, v. 28, n. 5, p. 491-520, 2006.

FRANCO, M. L. P. B. Análise do Conteúdo. 2. ed. Brasília: Liber Livro Editora, 2005.

FREGUGLIA, J. M. G. A produção de sentidos no contexto de uma aula de ciências sobre a adaptação biológica mediada por um desenho de animação. 2009. 108f. Dissertação (Mestrado em Educação, área de concentração: Educação e Ciências) - Faculdade de Educação, Universidade Federal de Minas Gerais, Belo Horizonte, 2009.

FUTUYMA, D. J. Biologia evolutiva. Ribeirão Preto: FUNPEC-RP, 2006.

GOEDERT, L. A formaşão do professor de biologia na UFSC e o ensino da evolução biológica. 2004. $122 \mathrm{f}$. Dissertação (Mestrado em Educação Científica e Tecnológica) - Programa de Pós-graduação em Educação Científica e Tecnológica, Universidade Federal de Santa Catarina, Florianópolis, 2004.

HALLIDAY, M. A. K.; MARTIN, J. R. Writing science: Literacy and discursive power. Pittsburgh, PA: University of Pittsburgh Press, 1993.

HARRISON, R.G. Book review. Nature, n. 411, p. 635-636, 2001.

KUHN, D. Science as argument: Implications for teaching and learning scientific thinking. Science Education, v. 77, n. 3, p. 319-337, 1993.

LEÃO, F. B. F.; MEGID-NETO, J. Avaliações oficiais sobre o livro didático de Ciências. In: FRACALANZA, H.; MEGID-NETO, J. (orgs.) O livro didático de Ciências no Brasil. 1. ed. Campinas: Editora Komedi, 2006. p. 35-79.

MAYR, E. O lugar da biologia nas ciências e sua estrutura conceitual. In: Desenvolvimento do pensamento biológico: diversidade, evolução e herança. Brasília: Editora Universidade de Brasília, 1998. p. 37-103.

A autonomia da Biologia. In: Biologia, ciência única: reflexões sobre a autonomia de uma disciplina científica. São Paulo: Companhia das Letras, 2005. p. 36-54.

. Como a biologia explica o mundo vivo? In: . Isto é biologia: a ciência do mundo vivo. São Paulo: Companhia das Letras, 2008. p. 97-115.

MILLAR, R.; OSBORNE, J. Beyond 2000: science for the future. London: King's College, 1998.

MORTIMER, E. F.; CHAGAS, A. N.; ALVARENGA, V. T. Linguagem científica versus linguagem comum nas respostas escritas de vestibulandos. Investigacõoes em Ensino de Ciências, v. 3, n. 1, p. 7-19, 1998.

NORRIS, S. P.; PHILLIPS, L. How literacy in its fundamental sense is central to scientific literacy. Science Education, v. 87, n. 2, p. 224-240. 2003.

NORRIS, S. P.; GUILBERT, S. M.; SMITH, M. L.; HAKIMELAHI, S.; PHILLIPS, L. M. A theoretical framework for narrative explanation in science. Science Education, v. 89, n. 4, p. 535-563, 2005.

POZO, J. I.; GÓMEZ CRESPO, M. A. A aprendizagem e o ensino de Ciências: do conhecimento cotidiano ao conhecimento científico. 5. ed. Porto Alegre: Artmed, 2009. 
RIBEIRO, R. M. L.; MARTINS, I. O potencial das narrativas como recurso para o ensino de ciências: uma análise em livros didáticos de Física. Ciência \& Educação, v. 13, n. 3, p. 293-309, 2007.

RIDLEY, M. O surgimento da Biologia Evolutiva. In: . Evolução. 3. ed. Porto Alegre: Artmed, 2006. p. 27-44.

ROMA, V. N. Os livros didáticos de biologia aprovados pelo programa nacional do livro didático para o ensino médio (PNLEM 2007/2009): a evolução biológica em questão. 2011. 229f. Dissertação (Mestrado em Ensino de Ciências) - Faculdade de Educação, Universidade de São Paulo, São Paulo, 2011.

SANTOS, C. M. D.; CALOR, A. R. Ensino de biologia evolutiva utilizando a estrutura conceitual da sistemática filogenética - II. Ciência \& Ensino, v. 2, n. 1, 2007.

SANZ, M. M. De la taxonomía tradicional a las filogenias moleculares. Real Sociedad Española de Historia Natural (Séccion Biológica), v. 100, n. 1-4, p. 45-65, 2005.

SILVA-PORTO, F. C.; LUZ, M.; WAIZBORT, R. A suposta centralidade da Evolução nos livros didáticos de Biologia. In: ENCONTRO NACIONAL DE PESQUISA EM EDUCAÇÃO EM CIÊNCIAS, 4., 2007. Florianópolis, Caderno de Resumos do VI Encontro Nacional de Pesquisa em Educação em Ciências, p. 127-127. Disponível em: <http://www.nutes.ufrj.br/abrapec/vienpec/CR2/p430. pdf> . Acesso em: 20 dez. 2012.

TIDON, R.; LEWONTIN, R. C. Teaching evolutionary biology. Genetics and Molecular Biology, v. 27, n. 1, p. 124-131, 2004.

VASCONCELOS, S. D.; SOUTO, E. O livro didático de ciências no ensino Fundamental: proposta de critérios para análise do conteúdo zoológico. Ciência \& Educaşão, v. 9, n. 1, p. 93-104, 2003.

XAVIER, M. C. F.; FREIRE, A. S.; MORAES, M. O. A nova (moderna) biologia e a genética nos livros didáticos de biologia no ensino médio. Ciência \& Educação, v. 12, n. 3, p. 275-289, 2006.

YORE, L. D.; HAND, B.; GOLDMAN, S. R.; HILDEBRAND, G. M.; OSBORNE, J. F.; TREAGUST, D. F.; WALLACE, C. S. New Directions in Language and Science Education Research. Reading Research Quarterly, v. 39, n. 3, p. 347-352, 2004.

ZAMBERLAN, E. S. J. \& SILVA, M. R. O evolucionismo como princípio organizador da biologia. Temas \& Matizes, n. 15, p. 27-41, 2009.

Participação dos autores no artigo:

Jeronymo Dalapicolla: colaborou na coleta e análise dos dados e na redação do artigo.

Victor de Almeida Silva: colaborou na coleta e análise dos dados.

Junia Freguglia Machado Garcia: orientação do trabalho de coleta de dados, de análise dos dados e de redação do artigo.

Data recebimento: 09/01/2014

Data Aprovação: 09/12/2014

Data Versão Final: 02/01/2015

\section{Contato:}

Jeronymo Dalapicolla

Av. Fernando Ferrari, 514 - Goiabeiras, Vitória - ES, Brasil - 29075-910

Email: jdalapicolla@gmail.com 